\title{
Wear Behavior of Different Generations of Zirconia: Present Literature
}

\author{
Kuljirarnat Jitwirachot, ${ }^{1}$ Pimduen Rungsiyakull ${ }^{\circ},{ }^{1}$ Julie A. Holloway, ${ }^{2}$ \\ and Wissanee Jia-mahasap ${ }^{1}{ }^{1}$ \\ ${ }^{1}$ Department of Prosthodontics, Faculty of Dentistry, Chiang Mai University, Chiang Mai, Thailand \\ ${ }^{2}$ Department of Prosthodontics, The University of Iowa, Iowa City, IA, USA \\ Correspondence should be addressed to Wissanee Jia-mahasap; wissanee.j@cmu.ac.th
}

Received 11 November 2021; Revised 16 January 2022; Accepted 10 February 2022; Published 7 March 2022

Academic Editor: Cesar Rogério Pucci

Copyright ( $) 2022$ Kuljirarnat Jitwirachot et al. This is an open access article distributed under the Creative Commons Attribution License, which permits unrestricted use, distribution, and reproduction in any medium, provided the original work is properly cited.

\begin{abstract}
Objective. The wear behavior of the novel zirconia generation is less well understood and may be affected by compositional modifications compared to the conventional zirconia. Materials and Methods. Combinations of keywords such as "zirconia," "high translucent," and "wear" were searched in PubMed and Google Scholar databases up to May 2021. The total of 23 relevant articles was selected according to inclusion criteria. Results. Reports show comparable wear resistance of translucent zirconia to the conventional zirconia despite an increased cubic phase content and lower mean flexural strength. A meticulously polished surface creates the lowest surface roughness, producing favorable zirconia wear resistance and antagonist wear compared to a glazed surface. In comparison to other ceramic materials, zirconia produces the least wear on an enamel antagonist and almost undetectable wear when opposed by zirconia. Wear when paired against resin materials yields a favorable outcome, whereas wear behavior against a metal antagonist varies with the surface hardness of the metal. Conclusions. All zirconia generations are considered wear-friendly to all types of antagonists. Nonetheless, comparative studies on antagonist wear opposing zirconia of different compositions are still limited and further investigation is required.
\end{abstract}

\section{Introduction}

With a rising demand from patients for highly esthetic dental restorations, various tooth-colored restorative materials have been introduced in the past decades. Zirconia rapidly gained popularity due to several advantages including good esthetics, biocompatibility, and outstanding mechanical properties comparing to other ceramic systems. In addition, increasing prices of precious alloys and mechanical failure of metal-ceramic restorations have made zirconia a novel restoration of choice.

Three generations of zirconia have been developed to date. Initially, conventional 3Y-TZP (3 mol\% yttria-stabilized tetragonal zirconia polycrystal) was utilized as a framework material that was veneered by more conventional ceramics to achieve an esthetic result, as this first-generation dental zirconia was very opaque. Its high strength allowed multiunit applications, but chipping and failure of the weaker veneering ceramic were common. The latter two generations, shared termed "high-translucency" zirconia, aim to overcome esthetic problems, namely, high opacity, exhibited by previous generations of zirconia. Improved translucency of zirconia from the second generation was achieved through reduction of alumina additive content to $0.05 \%$ by weight while yttrium oxide stabilizer remains unchanged at $3 \%$ by mol ( $4.5-5.6 \%$ by weight) [1]. Further translucency is enhanced with rising yttrium oxide content above $4 \%$ by $\mathrm{mol}(<10 \%$ by weight) along with the amount of cubic phase zirconia. These modifications lead to plausible application of zirconia as monolithic restoration without the need for veneering. However, while the change in chemical composition to improve the optical properties does not significantly affect the physical and mechanical properties of second-generation zirconia, the modifications adversely 
lessen those of the third-generation zirconia [1]. Our review will focus on the effects of these compositional changes in the different generations of zirconia on wear resistance.

Investigation of opposing enamel and restoration surface wear is of equal importance. Conventional wisdom, based on wear of feldspathic ceramics opposing natural dentition, has suggested that a new zirconia restoration should not be placed opposing unrestored enamel surfaces. Likewise, interaction of zirconia restoration with other types of restorative material was concerned. Additionally, wear resistance of the zirconia restorations itself is noteworthy. Therefore, our review aims to discuss the wear behavior of zirconia as well as its opposing materials and provide evidence that will be useful for making a clinical decision when selecting the appropriate material for fixed restorations.

A literature search of electronic databases was conducted using PubMed and Google Scholar databases up to May 2021. The search keywords included combinations of terms such as "zirconia," "high-translucent," and "wear." Experimental studies, both in vitro and in vivo, involving wear of monolithic zirconia and its opposing materials of any types were included. The publication must be in English language. Case report and non-peer-reviewed articles were excluded. From all search results appeared on the database, only 23 available articles were selected after analyzing for relevant titles and abstracts. The flowchart of article selection is illustrated in Figure 1.

\section{Zirconia in Dentistry}

Zirconia material is originally known for its superior flexural strength and surface hardness. High surface hardness was expected to produce more antagonist wear $[2,3]$. This statement holds true for metals, which wear through plastic deformation $[4,5]$. However, evidence suggests a poor correlation between ceramic materials and surface hardness because of their brittle nature [6]. Accordingly, the wear mechanism of ceramics is abrasive wear as a result of surface microfracture [7]. Ability to withstand external force and maintain surface integrity depends on properties of the material. Therefore, understanding the variation of zirconia, both chemically and mechanically, which might have an influence on wear behavior is crucial.

2.1. Basic Information. Zirconia or zirconium dioxide $\left(\mathrm{ZrO}_{2}\right)$ is a polymorphic material existing in three crystalline phases: monoclinic, tetragonal, and cubic (Figure 2). It can undergo phase transformation under the influence of temperature or stress. Without chemical modification, zirconia crystalizes in its cubic phase ( $c$ phase) during cooling first at temperatures below $2,680^{\circ} \mathrm{C}$. It then transforms to the tetragonal phase ( $t$ phase) at $2,370^{\circ} \mathrm{C}$ and lastly to the monoclinic phase ( $m$ phase) under $1,770^{\circ} \mathrm{C}$. The latter phase transformation causes volumetric expansion of approximately $4 \%$. Such sudden change in volume creates high tension and undesirable crack formation in the ceramic. Initially, $3 \mathrm{~mol} \%$ yttria or yttrium oxide was added to zirconia to prevent this phase transformation $[1,8]$.

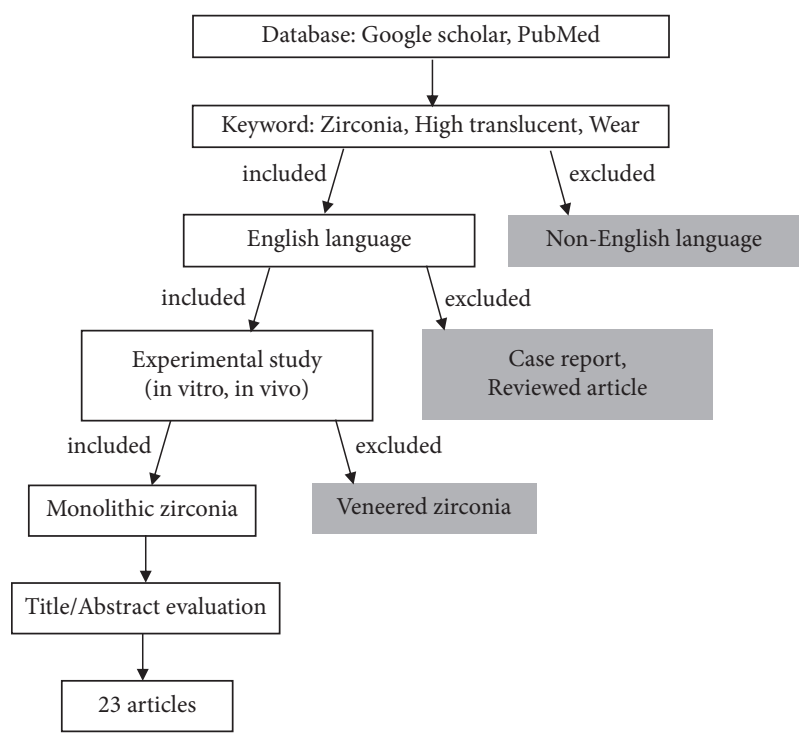

FIgURE 1: Article selection flowchart.

Yttria-stabilized zirconia has a unique property which brings about its high strength. First-generation zirconia is stabilized in the tetragonal phase with $3 \mathrm{~mol} \%$ yttria preventing it from transforming to the monoclinic phase. However, exposure to mechanical stress and subsequent crack initiation leads to localized phase transformation. The change to monoclinic phase results in volumetric expansion, and a compressive force is produced at the advancing crack front, essentially "pinching" the crack closed. This prevents the crack from propagating and therefore increases the strength of 3Y-TZP. This phenomenon is called transformation toughening (Figure 3). This event may also help maintain surface integrity and smoothness which may reduce antagonist wear [9].

Another phase transformation in zirconia is called lowtemperature degradation (LTD) or aging. This phenomenon happens slowly from water penetration into crystalline structure at $200-400^{\circ} \mathrm{C}$ well below sintering temperature. Repeated exposure to warm and humid environment gradually transforms phases of zirconia from tetragonal to monoclinic. The rate of LTD, stated in a study by Koenig et al. in 2006, is approximately 15 years or comparable to the mean lifespan of dental restorations [10]. Phase transformation from LTD potentially could roughen the surface of zirconia along with the formation of microcrack [11].

An addition of alumina content of at least $0.15 \mathrm{wt} \%$ helps reduce low-temperature degradation. Reduction of alumina content to enhance zirconia translucency can increase predisposition to LTD. Nevertheless, alumina sintering additives also lead to higher opacity, a competing outcome for dental use.

\subsection{Generation of Zirconia}

2.2.1. First Generation. The first generation of zirconia was introduced to dentistry over two decades ago as yttria-stabilized tetragonal zirconia polycrystal (Y-TZP). It contains 


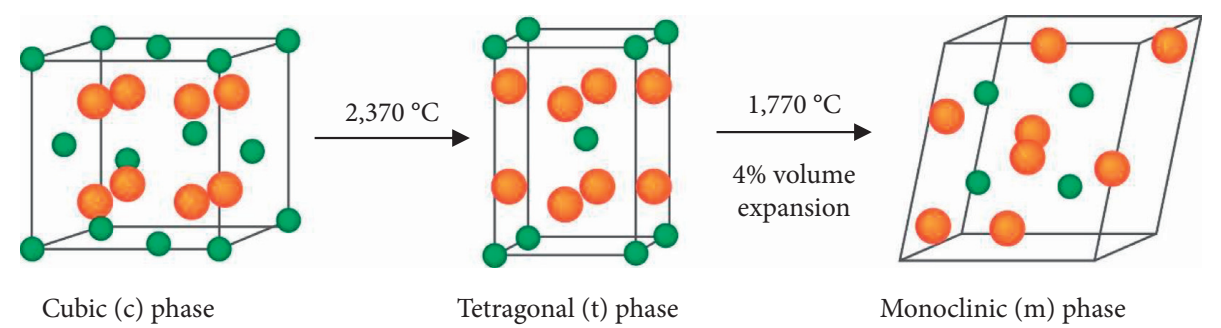

FIgURe 2: Phase transformation of zirconia.
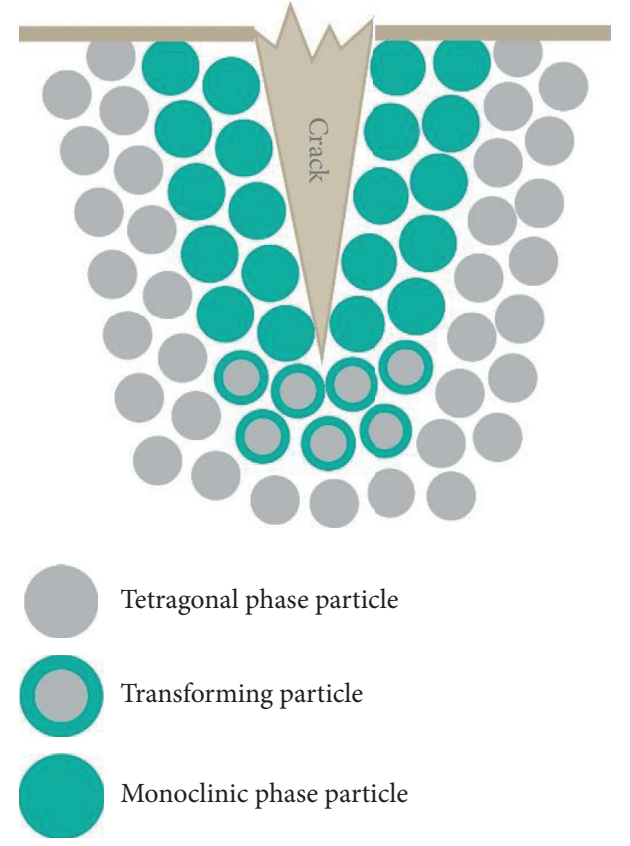

FIgURE 3: Transformation toughening.

$3 \%$ mol of yttria with at least 90 percent of tetragonal zirconia, giving its name, 3 Y-TZP. Despite superior mechanical property with flexural strength over $1000 \mathrm{MPa}[1,12]$, this generation of zirconia has opaque characteristics which limit its use in esthetic areas. Alteration of the sintering protocol was attempted to improve translucency. Unfortunately, it adversely decreased flexural strength and does not succeed [1]. This compromised optical property of conventional zirconia necessitates the use of veneering porcelain over the zirconia framework to mask its opacity [13]. Therefore, as with conventional metal-ceramic restorations, frequent chipping of veneering porcelain was observed and was reported as ranging from $0-54 \%$ annually [14].

2.2.2. Second Generation. The second generation of zirconia was proposed to solve the frequent chipping problem as a monolithic or single-layered restoration [15]. Furthermore, in addition to elimination of the unwanted chipping complication, monolithic restorations require less invasive nature, tooth reduction, and less laboratory time and cost to fabricate [16]. However, the main composition is still 3\% mol of yttria with at least 90 percent of tetragonal zirconia. Better translucency was achieved by reduction of alumina additive content from $0.25 \%$ to $0.05 \%$ by weight. Alumina has a large refractive index mismatch with zirconia which leads to light scattering and diminishes zirconia translucency. A reduction in lumina content, as well as alumina molecule rearrangement, allows higher light transmission [17, 18]. These changes brought about the second generation of dental zirconia. It still exhibits comparable flexural strength to the first generation at $1000 \mathrm{MPa}$, ten times higher than veneering porcelain, without jeopardizing stability and strength of the zirconia [1, 19]. In addition, staining and glazing can enhance esthetics and mimic a natural appearance. However, with only $70 \%$ of the translucency of lithium disilicate, the second generation of dental zirconia still did not provide adequate esthetics for use in anterior teeth [13].

2.2.3. Third Generation. The third and the latest generation of zirconia exhibits a modified crystalline structure containing increased percentages of cubic phase in pursuit of even greater translucency. "High-translucent" or "ultratranslucent" zirconia refers to this specific generation. The geometry of different zirconia phases affects light transmission behavior and translucency. The tetragonal phase has birefringent properties, or anisotropic refractory index, which results in a greater amount of light scattering at grain boundaries. On the other hand, the cubic phase has isotropic refractory index without scattering effect which offers better translucency.

Increasing the content of yttria to $4 \%$ and $5 \%$ mol results in higher nontransformable cubic phase and lesser tetragonal phase, consequently increasing translucency. Elemental analysis through X-ray diffraction (XRD) by Zhang et al. revealed about $40 \%$ and $60 \%$ of cubic phase content in $4 \mathrm{Y}$ and 5Y-TZP, respectively [20]. Other studies also report an increased amount of cubic phase of up to $53 \%$ in this thirdgeneration zirconia (5Y-TZP) $[1,18]$.

It is noteworthy that there are some confusions on the term "translucent zirconia" since both second and third generations are frequently called by the same nomenclature. The term "monolithic zirconia" without any further description is normally referred to 3Y-TZP from the second generations, while studies on the third generation are usually more specific [21-24]. However, detailed compositions of commercial products are scarcely provided by the manufacturers or researchers. Some available information on manufacturers and compositions was summarized in a review by Kontonasaki et al. [25]. 


\subsection{Property Changes in the Third Generation}

2.3.1. Optical Properties. Improvement in translucency of 5Y-TZP was evaluated in multiple studies [23, 26, 27]. 5YTZP has the highest translucency among other generations of zirconia owing to greater amount of cubic zirconia and its grain size. It appears to occupy a place between lithium disilicate (IPS e.max CAD LT) and conventional 3Y-TZP zirconia, in terms of both translucency and flexural strength $[1,20,23,28]$. Baldissara et al. conducted a comparative study in 2008 on contrast ratio between lithium disilicate glass ceramic and 5Y-TZP zirconia using an anatomic crown shape with clinically recommended occlusal thickness. The result revealed no significant difference in translucency [29]. Regardless of material color, the translucency of zirconia is less influenced by thickness unlike lithium disilicate $[1,12,30,31]$. Expected light transmittance percentage of $5 \mathrm{Y}-\mathrm{TZP}$ as claimed by the manufacturers is still more opaque than average human dentin.

2.3.2. Mechanical Properties. The mechanical properties of high-translucency zirconia are manufacturer-dependent. Even though increased cubic phase enhances translucency, it negatively influences strength of high-translucent zirconia. Cubic zirconia does not possess the transformation toughening phenomenon as does tetragonal zirconia. Less transformation can be detected in $4 \mathrm{Y}-\mathrm{TZP}$, but no evidence is shown in 5Y-TZP [20]. The deprivation of this unique property of previous generations leads to a reduction in flexural strength in 5Y-TZP to about one-half to two-thirds of 3Y-TZP [18,20,23, 27, 32-35]. Clinical applications might be more suitable for low stress-bearing areas. Although 5Y-TZP exhibits higher fracture resistance compared to lithium disilicate when tested at unbounded state, they demonstrate similar fracture strength when bonded to dentin-like substrate at 0.5 and $1 \mathrm{~mm}$ thickness and inferior fracture strength for 5Y-TZP at $1.5 \mathrm{~mm}$ thickness [36].

The transformation toughening phenomenon is a unique property which contributes to the high strength of 3Y-TZP zirconia by reducing crack propagation and increasing fracture toughness $[1,9]$. This event may also help maintain surface integrity and smoothness which consequently reduces antagonist wear [9]. Without this specific property in 5Y-TZP zirconia, surface integrity and wear resistance may be affected. Conversely, the lack of phase transformation prevents low-temperature degradation $[1,18,33,34]$, and surface smoothness might be thereby compensated. However, concerns about wear resistance of third-generation zirconia should still be noted.

\section{Wear Behavior of Zirconia}

In terms of occlusal wear, ideal restorative materials should possess a similar wear rate to physiological enamel wear rate which ranges from 30 to $40 \mu \mathrm{m}$ per year in molar area and relatively lesser as the position in arch moves anteriorly $[3,37,38]$. A mismatch in wear rate between opposing teeth may result in excessive wear and lead to impaired esthetics and function $[39,40]$. Two aspects of interest in terms of wear have been discussed, namely, wear of the material itself and wear of its antagonist which is affected by material abrasiveness.

3.1. Factors Related to Zirconia Wear. Wear mechanism is multifactorial. Physiological variations among patients and material-based factors both play an important role in the wear process. Factors influencing wear of ceramics were thoroughly reviewed by $\mathrm{Oh}$ et al. in 2002 including physical factors, microstructural factors, chemical factors, and surface finishing [5].

3.1.1. Physical Factors. Ceramic materials have low resistance to tensile stress due to their brittle nature, which leads to surface chipping or fracture either from physiologic wear or iatrogenic surface adjustment [7]. With its higher fracture toughness, zirconia is less predisposed to crack formation. Also, transformation toughening counteracts crack propagation. Therefore, zirconia has an ability to maintain surface integrity under higher stress compared to other dental ceramics.

Frictional coefficient, a ratio of frictional force between two sliding surfaces in relation to the normal force pressing the two surfaces together, is varied by occlusal anatomical variations, degree of mandibular movement, masticatory load, chewing rate, types of contacting materials, and surrounding environment [5]. Patients with a wider range of movement or parafunctional habits, as well as greater masticatory load and/or sliding velocity, tend to generate a higher frictional load, resulting in greater wear $[5,41]$. However, these physiological factors cannot be altered by the dentist.

Irregularities in a ceramic surface contribute to surface roughness which can significantly accentuate antagonist wear in ceramic material itself and the opposing surface $[5,42,43]$. Roughened zirconia surfaces increase not only the wear of the opposing surface but also the incidence of chipping. Surface treatment methods and intraoral occlusal adjustment affect degree of surface roughness. Hence, an optimal smooth surface would benefit long-term reliability [44].

3.1.2. Microstructural Factors. Differences between the microstructures of glass ceramics and polycrystalline ceramics contribute to the difference in their wear behavior and wear mechanism. Glass ceramics are composed of crystalline particles incorporated into glassy matrix. Their principal wear mechanism relies on fatigue fracture of the glassy matrix with consequent exposure and loss of embedded crystalline phase [45]. Variations in base mineral types, amount, configuration, and distribution of these crystals are responsible for the abrasiveness of each ceramic [46]. On the other hand, polycrystalline ceramics exhibit a dense crystalline phase composition with little or no glassy phase. These polycrystalline ceramics are distinguished by high fracture toughness and wear through an abrasive wear mechanism where minor grain dislodgment is observed 
under scanning electron microscopy but no microcrack or chipping fragments are typically seen [47-51]. Although having similar fracture toughness and strength, lithium disilicate glass and 5Y-TZP display distinctly different wear behaviors due to differences in their microstructure [47].

Besides surface irregularities generated from functional wear, defects and porosities from the manufacturing process also aggravate the wear process on opposing surfaces once subsurface pores are exposed, leading to sharp asperities $[7,52]$.

3.1.3. Chemical Factors. Variations in $\mathrm{pH}$ values affect zirconia in a different way. In one study, low coefficients of friction and wear rates were observed in acidic environments below $\mathrm{pH}$ 4. The surface roughness of zirconia was not affected and actually decreased after exposure to acid, owing to a tribocorrosion process [53]. In contrast, a greater coefficient of friction and wear rate were observed in an intermediate to high $\mathrm{pH}$ environment. In highly alkaline environments, severe surface fractures and large dislodged fragments were detected, as well as phase transformation induced by low-temperature degradation [53, 54]. However, fluctuation of intraoral $\mathrm{pH}$ from normal value about 7-7.3 to higher $\mathrm{pH}$ values is uncommon but to lower $\mathrm{pH}$ could occur in patients with regurgitation of gastric content, acidic intakes, or mouth breathing $[5,55]$. Although zirconia restoration might survive under acidic environment, wear of opposing dental hard tissue or glass ceramics would be aggravated [5]. Under the similar acidic condition, ability to maintain surface integrity of zirconia would be more beneficial to opposing surface compared to increase in surface roughness and abrasiveness of glass ceramic restoration which undergo etching and glass corrosion process [5].

3.1.4. Surface Finishing. Surface finishing is associated with surface roughness and wear of zirconia. Comparison of glazed and polished surfaces has been widely studied. Most of the studies on zirconia surface finishing are in agreement with the polishing methods used to produce the least wear of the zirconia itself and the antagonist [49, 56-62]. Glazed surfaces may appear almost mirror-like at first glance from filling and leveling the rough surface. However, after a short period of time, the thinly applied glaze layer wears off and reveals a rougher, unpolished surface underneath resulting in increased antagonist abrasion $[26,51,57,58]$. Polishing prior to glazing reduces chance of excessive surface wear [63]. Repolishing after the surface has lost its glaze is also recommended [64]. Moreover, occlusal adjustment using diamond burs significantly roughens the adjusted area and requires proper finishing and polishing afterward [59-61].

Different polishing systems and polishing protocols by researchers produce varying degrees of surface roughness. The grit of diamond bur used for adjustment also correlates to postadjustment surface roughness. Adjustment of zirconia with a fine $30 \mu \mathrm{m}$ grit bur produces statistically comparable wear of opposing enamel as that of polished zirconia, while adjustment with a coarse $100 \mu \mathrm{m}$ grit bur generates substantially increased wear [57]. A fine diamond bur produces a surface roughness of approximately $1.18 \mu \mathrm{m}$, but for a coarse diamond bur, surface roughness is reported to be as high as $3.95 \mu \mathrm{m}$. The threshold value of ceramic surface roughness $(\mathrm{Ra})$ that significantly raises enamel wear based on several studies is over $1.5 \mu \mathrm{m}[57,65,66]$. Nonetheless, when comparing wear of enamel after zirconia adjustment with a fine $30 \mu \mathrm{m}$ grit bur vs. zirconia polishing burs, a statistically significant decrease in surface roughness and wear was reported from polishing [63]. Regarding the selection of zirconia polishing systems, diamond-impregnated silicone burs specifically designed for zirconia and other high strength ceramics are more effective in generating a smoother monolithic zirconia surface than silicon carbideimpregnated silicone burs, designed for porcelain polishing $[67,68]$. A meticulously polished surface using the appropriate burs should provide a surface roughness as low as $0.1-0.4 \mu \mathrm{m}[56,63,69]$. Force and friction applied during polishing, although while producing some local heat and stress, neither effect surface roughness nor create stressinduced $t-m$ phase transformation $[56,68,69]$. In addition, low surface roughness produced from polishing results in enhanced wear resistance and phase transformation resistance during the wear process of zirconia [56]. Even if differences in surface treatment have a direct effect on wear rate of the opposing surface, all abraded zirconia specimens showed no visible signs of wear regardless of surface treatment protocols [63].

Application of external staining material is another factor promoting wear since the composition of extrinsic stains contains abrasive metal oxides [5]. The surface roughness of zirconia, as well as antagonist wear volume, was reported to be greater after staining [62]. Therefore, its application should be restricted only to the surfaces not in occlusal contact.

3.2. Wear Resistance of Zirconia. Studies on various dental restorative materials have stated that materials with high strength and high fracture toughness showed minimal material wear or antagonist wear $[5,21,50,51,58]$. Scanning electron microscopy of zirconia also reveals a tightly bound grain structure which resists surface degradation [21]. Previous reviews on the mechanical properties of hightranslucent zirconia showed that the higher yttria content in cubic zirconia negatively influences fracture toughness and flexural strength of zirconia $[18,20,70]$. On the other hand, low-temperature degradation which induces surface roughness and subsurface crack formation is less in cubic zirconia than stabilized zirconia compositions [11]. This might consequently affect wear of the materials.

Concerns involving surface stability have led to studies evaluating wear behavior among the different zirconia generations. Most of the previously published studies were conducted with $3 \mathrm{Y}-\mathrm{TZP}$, and there is little information on wear behavior of high-translucent zirconia with increased yttria content. However, a few recent studies have compared wear behavior between $3 \% \mathrm{~mol}$ and $4-5 \%$ mol yttria-stabilized zirconia [21-24, 47]. 3Y-TZP, 4Y-TZP, and 5Y-TZP zirconia compositions exhibited minimal to unmeasurable 
wear volume loss regardless the type of antagonists including human enamel, steatite ball, or 3Y-TZP [21-23, 47]. In addition, most of the abraded zirconia specimens showed no wear crater and only slight surface scratches when examined under scanning electron microscopy using low magnification [21, 23, 47, 51]. Nevertheless, the grain dislodgment phenomenon accounts for the irregular pits that can be detected under high magnification, with larger pits seen in 5Y-TZP according to its larger grain size [47]. SEM images from Zhang et al. showed no crack formation in any worn zirconia specimens, particularly in 5Y-TZP which has a similar fracture toughness and strength to lithium disilicate [47]. In another study, a more aggressive wear pattern was observed in a comparative study by Vardhaman et al. Multilayered zirconia with a 5Y-TZP enamel layer and $4 \mathrm{Y}-$ TZP dentin layer was more susceptible to fatigue wear than monochromatic, monolithic 3Y-TZP. SEM evaluation also revealed a more advanced stage of wear progress in multilayered zirconia. Despite the variance in wear patterns, quantitative wear loss of the two materials suggested only minor differences [24].

It can be assumed that wear behavior is relatively unaffected by microstructural variations between zirconia generations and zirconia with increased yttria content is able to maintain good surface integrity despite lower flexural strength and fracture toughness [21, 23, 24, 47]. However, studies on the wear of unlayered first-generation zirconia are rare, since their occluding surfaces are usually layered with veneering porcelain. A summary of the studies on wear resistance of zirconia is depicted in Table 1.

3.3. Antagonist Wear against Zirconia. Wear resistance of zirconia compared to other restorative materials has been extensively studied. A wide range of antagonist materials have been used, including enamel substitutions, such as steatite ball or IPS Empress, bovine enamel, both nonstandardized and standardized human enamel, and zirconia itself. Studies on antagonist material wear against zirconia are listed in Table 2.

3.3.1. Enamel Wear. In vivo studies on enamel wear opposing a monolithic zirconia crown found that average vertical wear of the enamel antagonist was considerably higher than the contralateral enamel controls at the same time interval $[3,74,75]$. A higher wear rate during the first 6 months suggested an initial running-in period followed by more steady wear afterward. Even though this rate was deemed higher than yearly physiologic enamel wear, evidence from other in vitro studies suggests that monolithic zirconia produced the least wear on enamel compared to other ceramics [71, 73, 83]. Furthermore, several studies have also stated minimal enamel wear when opposed to zirconia.

3.3.2. Wear of Other Restorative Materials. The wear behavior of zirconia restorations opposed by dental materials other than human enamel is of equal significance.
Unrestored opposing teeth are occasionally found. Comparative studies of various types of restorative materials when used against zirconia have also been performed $[21,50,78-82]$.

(1) Ceramics. The in vitro wear rate of various types of ceramics opposing a zirconia abrader has been studied. The level of surface wear is associated with the materials' flexural strength, fracture toughness, and microstructure. Glass and hybrid ceramics consist of crystal grains loosely bound in glassy or polymeric matrices. According to the brittle nature of ceramics, the wear mechanism is primarily via fatigue wear [81]. Gradual wear of matrix phase exposes crystals to microfracture and dislodgment, thus lowering the strength of the material and increasing the chance of surface fracture and wear [21]. Furthermore, the wear rate of lithium-based glass ceramics, leucite-based ceramics, and feldspathic porcelains increases, respectively, inverse to their flexural strength [50]. According to the literature, selection of a glass ceramic restoration to oppose against a zirconia restoration may result in more substantial wear of the glass ceramic side $[21,78]$.

(2) Metal. Existing metal restorations in good condition may serve many years in function without the need for replacement. Caution must be exercised when a new zirconia restoration is contemplated being placed opposing an existing metal alloy restoration in terms of wear. Unlike ceramics, the wear mechanism of metal is associated with surface hardness and plastic deformation [4,5]. The wear mechanism between metal alloys and zirconia is mainly abrasive wear, although some delamination wear was shown to occur in some circumstances [79]. Nevertheless, gold alloys show the greatest material loss as a consequence of their low hardness when abraded against monolithic zirconia, compared to nickel-chromium alloys and cobaltchromium alloys, respectively [79]. Base metal alloys, with their greater surface hardness, are expected to possess higher wear resistance but more opposing antagonist wear [79]. SEM imaging reveals a roughened surface, surface cracking, and phase transformation of 3Y-TZP zirconia after abraded against cobalt-chromium alloys. Therefore, pairing of these two materials in a clinical setting is not recommended [79].

(3) Polymer and Composite. Use of different materials in fullarch implant-supported prostheses may be advocated to limit mechanical complications in the opposing, weaker arch. Accordingly, denture teeth supported by a metal framework are often chosen as an antagonist against a zirconia full-arch implant-supported prosthesis $[84,85]$.

The chemical compositions of resin matrix and filler in denture teeth influence their wear resistance. Modification in composition and fabrication technique has been used by manufacturers to improve the strength and wear resistance of conventional polymethyl methacrylate (PMMA) denture teeth. CAD/CAM-fabricated and 3D-printed denture teeth have shown comparable wear resistance to prefabricated PMMA denture teeth against a zirconia abrader [80, 82]. 3D- 
TABLE 1: Studies investigating wear resistance of zirconia specimens.

\begin{tabular}{|c|c|c|c|c|c|c|c|}
\hline Authors & $\begin{array}{c}\text { Yttria } \\
\text { content } \\
{[25]}\end{array}$ & $\begin{array}{l}\text { Zirconia } \\
\text { system }\end{array}$ & $\begin{array}{l}\text { Zirconia } \\
\text { specimen }\end{array}$ & $\begin{array}{l}\text { Comparative } \\
\text { groups }\end{array}$ & $\begin{array}{l}\text { Antagonist } \\
\text { material }\end{array}$ & $\begin{array}{l}\text { Wear method: } \\
\text { parameter }\end{array}$ & Results \\
\hline $\begin{array}{l}\text { Janyavula et } \\
\text { al. [58] }\end{array}$ & $\begin{array}{c}3 \mathrm{~mol} \% \\
{[25]}\end{array}$ & $\begin{array}{l}\text { Ivoclar } \\
\text { Vivadent }\end{array}$ & Flat shape & $\begin{array}{l}\text { (1) Polished } \\
\text { zirconia } \\
\text { (2) Glazed zirconia } \\
\text { (3) Polished then } \\
\text { glazed zirconia }\end{array}$ & $\begin{array}{l}\text { Enamel } \\
\text { (premolar } \\
\text { cusp) }\end{array}$ & $\begin{array}{c}\text { University of } \\
\text { Alabama: } 10 \mathrm{~N} \text { load, } \\
\text { frequency of } \\
20 \text { cycles } / \mathrm{min}, 2 \mathrm{~mm} \\
\text { distance, } 400,000 \\
\text { cycles }\end{array}$ & $\begin{array}{l}\text { Small amount of wear } \\
\text { was observed in glazed } \\
\text { and polished then } \\
\text { glazed, while wear } \\
\text { volume of polished } \\
\text { zirconia specimens } \\
\text { was unmeasurable. }\end{array}$ \\
\hline $\begin{array}{l}\text { Jung et al. } \\
\text { [71] }\end{array}$ & $\begin{array}{c}3 \mathrm{~mol} \% \\
{[25]}\end{array}$ & Prettau & $\begin{array}{l}\text { Cuboidal } \\
\text { shape }\end{array}$ & $\begin{array}{l}\text { (1) Zirconia } \\
\text { (i) Polishing } \\
\text { (ii) Glazing }\end{array}$ & $\begin{array}{l}\text { Enamel } \\
\text { (maxillary } \\
\text { premolar) }\end{array}$ & $\begin{array}{l}\text { SD Mechatronik: } \\
49 \mathrm{~N} \text { load, } 0.8 \mathrm{~Hz} \\
\text { frequency, } 0.3 \mathrm{~mm} \\
\text { distance, } 240,000 \\
\text { cycles }\end{array}$ & $\begin{array}{l}\text { Volume loss of } \\
\text { polished zirconia was } \\
\text { the lowest among all } \\
\text { groups presenting the } \\
\text { best wear resistance. } \\
\text { Glazed zirconia } \\
\text { showed better wear } \\
\text { resistance than } \\
\text { feldspathic porcelain } \\
\text { although not } \\
\text { statistically different. }\end{array}$ \\
\hline $\begin{array}{l}\text { Albashaireh } \\
\text { et al. [50] }\end{array}$ & $\begin{array}{c}3 \mathrm{~mol} \% \\
{[25]}\end{array}$ & $\begin{array}{l}\text { IPS e.max } \\
\text { ZirCAD }\end{array}$ & Disc shape & $\begin{array}{l}\text { (1) Zirconia } \\
\text { (2) Lithium } \\
\text { disilicate glass } \\
\text { ceramic } \\
\text { (3) Leucite- } \\
\text { reinforce glass } \\
\text { ceramic } \\
\text { (4) Fluorapatite } \\
\text { glass ceramic } \\
\text { (5) } \\
\text { Nanofluorapatite } \\
\text { glass ceramic }\end{array}$ & Zirconia ball & $\begin{array}{c}\text { Mastication } \\
\text { simulator: } 49 \mathrm{~N} \\
\text { load, } 1.3 \mathrm{~Hz} \\
\text { frequency, } 300,000 \\
\text { cycles }\end{array}$ & $\begin{array}{l}\text { Zirconia specimens } \\
\text { exhibited lowest } \\
\text { vertical and volume } \\
\text { loss compared to } \\
\text { other ceramics after } \\
\text { wear test. SEM images } \\
\text { revealed no crack or } \\
\text { defect on the surface } \\
\text { of zirconia. }\end{array}$ \\
\hline $\begin{array}{l}\text { Kwon et al. } \\
{[72]}\end{array}$ & $\begin{array}{c}3 \mathrm{~mol} \% \\
{[25]}\end{array}$ & Prettau & $\begin{array}{c}\text { Anatomic } \\
\text { crown } \\
\text { (substrate), } \\
\text { flat } \\
\text { (antagonist) }\end{array}$ & (2) Gold alloy type 3 & Zirconia & $\begin{array}{c}\text { TE77 Auto: } 50 \mathrm{~N} \\
\text { load, } 1 \mathrm{~Hz} \\
\text { frequency, } 15 \mathrm{~mm} \\
\text { distance, } 600 \text { cycles }\end{array}$ & $\begin{array}{l}\text { (i) Enamel specimen } \\
\text { wore at the highest } \\
\text { rate against zirconia } \\
\text { antagonist at the } \\
\text { statistically different } \\
\text { value from other two } \\
\text { groups. } \\
\text { (ii) Gold alloy and } \\
\text { zirconia represented } \\
\text { similar wear resistance } \\
\text { against zirconia. } \\
\text { (iii) The zirconia } \\
\text { antagonists, however, } \\
\text { were unblemished } \\
\text { under SEM after } \\
\text { tested with enamel } \\
\text { and gold and } \\
\text { presented only slight } \\
\text { wear line against } \\
\text { zirconia. }\end{array}$ \\
\hline
\end{tabular}


TABle 1: Continued.

\begin{tabular}{|c|c|c|c|c|c|c|c|}
\hline Authors & $\begin{array}{c}\text { Yttria } \\
\text { content } \\
{[25]}\end{array}$ & $\begin{array}{l}\text { Zirconia } \\
\text { system }\end{array}$ & $\begin{array}{l}\text { Zirconia } \\
\text { specimen }\end{array}$ & $\begin{array}{l}\text { Comparative } \\
\text { groups }\end{array}$ & $\begin{array}{c}\text { Antagonist } \\
\text { material }\end{array}$ & $\begin{array}{l}\text { Wear method: } \\
\text { parameter }\end{array}$ & Results \\
\hline $\begin{array}{l}\text { Nakashima et } \\
\text { al. [73] }\end{array}$ & $\begin{array}{c}3 \mathrm{~mol} \% \\
{[25]}\end{array}$ & $\begin{array}{l}\text { Aadva } \mathrm{Zr} \\
\text { (GC) }\end{array}$ & $\begin{array}{l}\text { Cone-shaped } \\
\text { stylus }\end{array}$ & $\begin{array}{l}\text { (1) Zirconia } \\
\text { (2) Lithium } \\
\text { disilicate glass } \\
\text { (3) Leucite- } \\
\text { reinforced glass } \\
\text { (4) Feldspathic } \\
\text { porcelain } \\
\text { (5) Enamel cusp } \\
\text { (molar) }\end{array}$ & $\begin{array}{l}\text { Enamel } \\
\text { (proximal } \\
\text { surface of } \\
\text { premolar) }\end{array}$ & $\begin{array}{c}\text { University of } \\
\text { Alabama: } 75 \mathrm{~N} \text { load, } \\
1.2 \mathrm{~Hz} \text { frequency, } \\
100,000 \text { cycles, } \\
\text { back-and-forth } \\
\text { rotating movement } \\
\text { of } 15^{\circ}\end{array}$ & $\begin{array}{l}\text { Zirconia stylus } \\
\text { showed very minimal } \\
\text { wear which was } \\
\text { substantially lower } \\
\text { than other materials. } \\
\text { Enamel antagonists } \\
\text { opposing zirconia also } \\
\text { presented with the } \\
\text { lowest wear. Glass } \\
\text { ceramics generated } \\
\text { similar wear of enamel } \\
\text { antagonist as the } \\
\text { enamel stylus and also } \\
\text { displayed similar wear } \\
\text { resistance. }\end{array}$ \\
\hline $\begin{array}{l}\text { Kwon et al. } \\
{[23]}\end{array}$ & $\begin{array}{c}3 \mathrm{Y}-\mathrm{TZP} \\
5 \mathrm{Y}-\mathrm{ZP}\end{array}$ & $\begin{array}{l}\text { Katana } \\
\text { HT } \\
\text { Katana } \\
\text { UTML }\end{array}$ & Flat shape & $\begin{array}{l}\text { (1) Polished } \\
\text { zirconia } \\
\text { (i) Katana HT (3Y- } \\
\text { TZP) } \\
\text { (ii) Katana UTML } \\
\text { (5Y-ZP) } \\
\text { (2) Lithium } \\
\text { disilicate } \\
\text { (3) Enamel (labial } \\
\text { surface of maxillary } \\
\text { central incisor) }\end{array}$ & $\begin{array}{c}\text { Enamel cusp } \\
\text { (mandibular } \\
\text { molars) }\end{array}$ & $\begin{array}{c}\text { University of } \\
\text { Alabama: } 20 \mathrm{~N} \text { load, } \\
0.4 \mathrm{~Hz} \text { frequency, } \\
2 \mathrm{~mm} \text { distance, } \\
300,000 \text { cycles }\end{array}$ & $\begin{array}{l}\text { Both } 3 \mathrm{Y} \text { - and 5Y-TZP } \\
\text { zirconia specimens } \\
\text { presented comparable } \\
\text { unmeasurable wear } \\
\text { volume, while another } \\
\text { two groups displayed } \\
\text { significant wear. SEM } \\
\text { images showed } \\
\text { neither surface } \\
\text { fracture nor } \\
\text { roughening of any } \\
\text { zirconia surface. } \\
\text { However, opposing } \\
\text { enamel cusps showed } \\
\text { no difference among } \\
\text { material groups. }\end{array}$ \\
\hline $\begin{array}{l}\text { Borrero- } \\
\text { Lopez et al. } \\
{[21]}\end{array}$ & $\begin{array}{l}3 \mathrm{Y}-\mathrm{TZP} \\
5 \mathrm{Y}-\mathrm{TZP} \\
\text { Graded }\end{array}$ & $\begin{array}{l}\text { Zpex } \\
\text { Zpex } \\
\text { Smile } \\
\text { Zpex } \\
\text { (graded) }\end{array}$ & Disc shape & $\begin{array}{l}\text { (i) Zpex (3Y-TZP) } \\
\text { (ii) Zpex Smile (5Y- } \\
\text { TZP) } \\
\text { (iii) Zpex (graded) } \\
\text { (2) Lithium } \\
\text { disilicate } \\
\text { (3) Feldspathic } \\
\text { ceramic } \\
\text { (4) Ceramic- } \\
\text { polymer composites } \\
\text { (5) Enamel }\end{array}$ & $\begin{array}{c}\text { Densely } \\
\text { sintered } \\
\text { zirconia ball } \\
(3 \mathrm{Y}-\mathrm{TZP})\end{array}$ & $\begin{array}{l}\text { Rotating ball-on-3- } \\
\text { flat tribometer: } 30 \mathrm{~N} \\
\text { load, } 30 \mathrm{rpm} \\
\text { frequency, total } \\
\text { contact distance of } \\
37 \mathrm{~m}\end{array}$ & $\begin{array}{l}\text { (i) All types of zirconia } \\
\text { specimens showed the } \\
\text { similar lowest wear } \\
\text { rate when tested } \\
\text { against 3Y-TZP } \\
\text { zirconia, which were } \\
\text { lower than other test } \\
\text { groups. } \\
\text { (ii) SEM images } \\
\text { revealed noticeable } \\
\text { scratch marks on the } \\
\text { surface of zirconia } \\
\text { although no wear scar } \\
\text { was observed, unlike } \\
\text { other materials where } \\
\text { obvious wear scars } \\
\text { were presented. }\end{array}$ \\
\hline
\end{tabular}


TABLE 1: Continued.

\begin{tabular}{ccccccc}
\hline Authors & $\begin{array}{c}\text { Yttria } \\
\text { content } \\
{[25]}\end{array}$ & $\begin{array}{c}\text { Zirconia } \\
\text { system }\end{array}$ & $\begin{array}{c}\text { Zirconia } \\
\text { specimen }\end{array}$ & $\begin{array}{l}\text { Comparative } \\
\text { groups }\end{array}$ & $\begin{array}{c}\text { Antagonist } \\
\text { material }\end{array}$ & $\begin{array}{c}\text { Wear method: } \\
\text { parameter }\end{array}$ \\
\hline
\end{tabular}

(i) Multilayered zirconia showed greater volume loss and deeper wear depth after simulation.

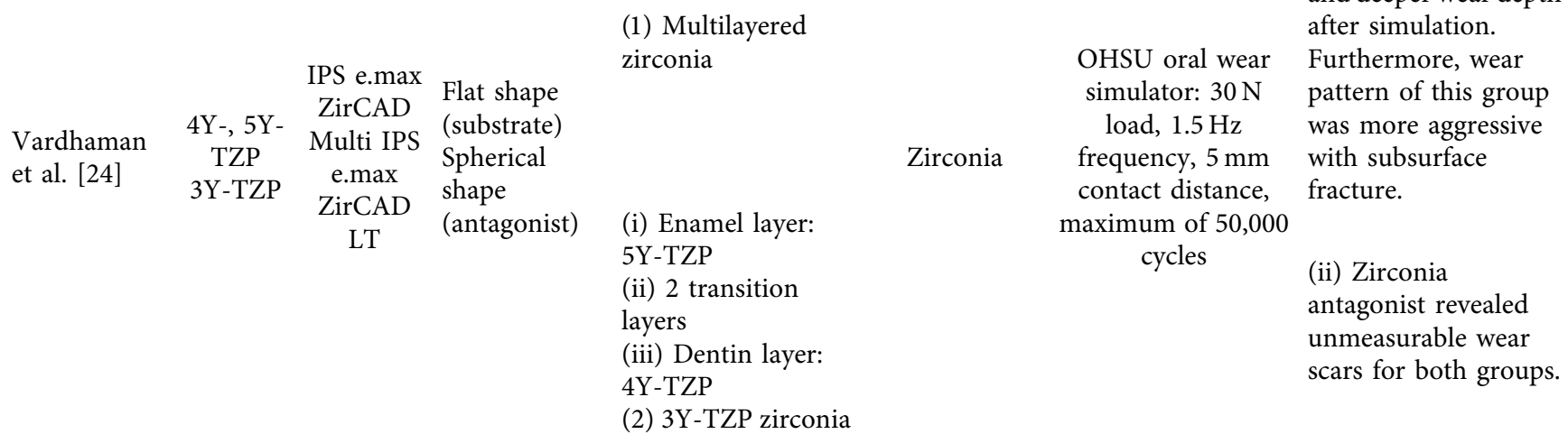

(i) All zirconia showed comparable wear behavior in either

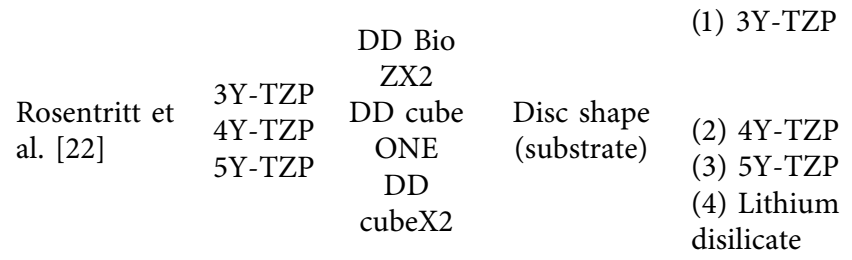

Pin-on-block wear material wear or test: $50 \mathrm{~N}$ load, antagonist wear.

(5) Enamel

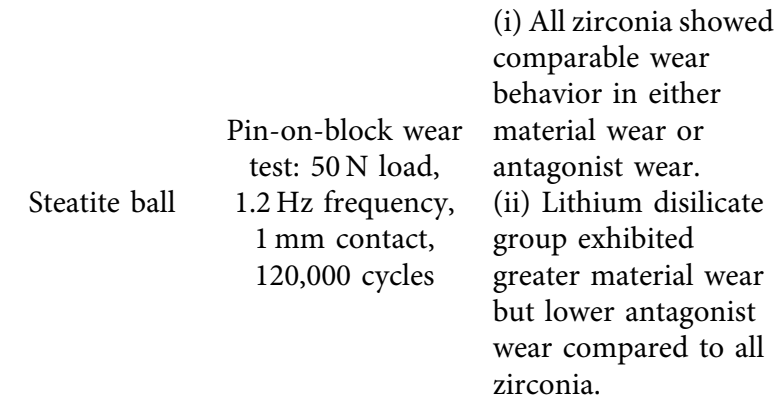

${ }^{*}$ Information on yttria content, which is not available in the original literature, is listed according to the review literature by Kontonasaki et al. [25]. Studies are listed in chronological order.

printed denture teeth often contain microbubble clusters under SEM inspection, which may initiate cracks after a functional load and period. Nevertheless, 3D-printed denture teeth remain relatively smooth after being abraded against zirconia, compared to the cracked and worn surfaces seen in worn prefabricated denture teeth [80]. PMMA denture teeth, regardless of their physical variations, show inferior wear resistance to resin composite denture teeth. This difference in wear resistance is consistent against both human enamel and zirconia [82, 86, 87]. A different wear mechanism has been described between unfilled polymer teeth, which were subjected to fatigue wear, and filled polymer or resin composite teeth that exhibit abrasive wear due to the presence of hard filler particles. Filled resin teeth provide superior wear resistance to unfilled ones under identical testing methodologies [80, 82].

The size and configuration of the filler particles themselves play an important role in the level of wear of resin composite. When abraded against a zirconia antagonist, microhybrid resin composite experienced higher volumetric substance loss as a consequence of its mixture of larger filler size and irregular filler shape compared to nanofilled resin composite.

\section{Clinical Relevance}

(i) Enamel wear against zirconia is considered clinically acceptable when zirconia is meticulously polished.

(ii) In a situation where ceramic restorations are required on opposing occluding surfaces, zirconia placed against itself provides the best wear resistance, while choosing different types of ceramics can predispose the materials to greater wear.

(iii) Placement of 3Y-TZP zirconia opposing a gold alloy restoration may result in increased wear on the gold alloy. On the contrary, placing zirconia against Co$\mathrm{Cr}$ alloy is neither recommended since phase transformation is expected in 3Y-TZP zirconia. 


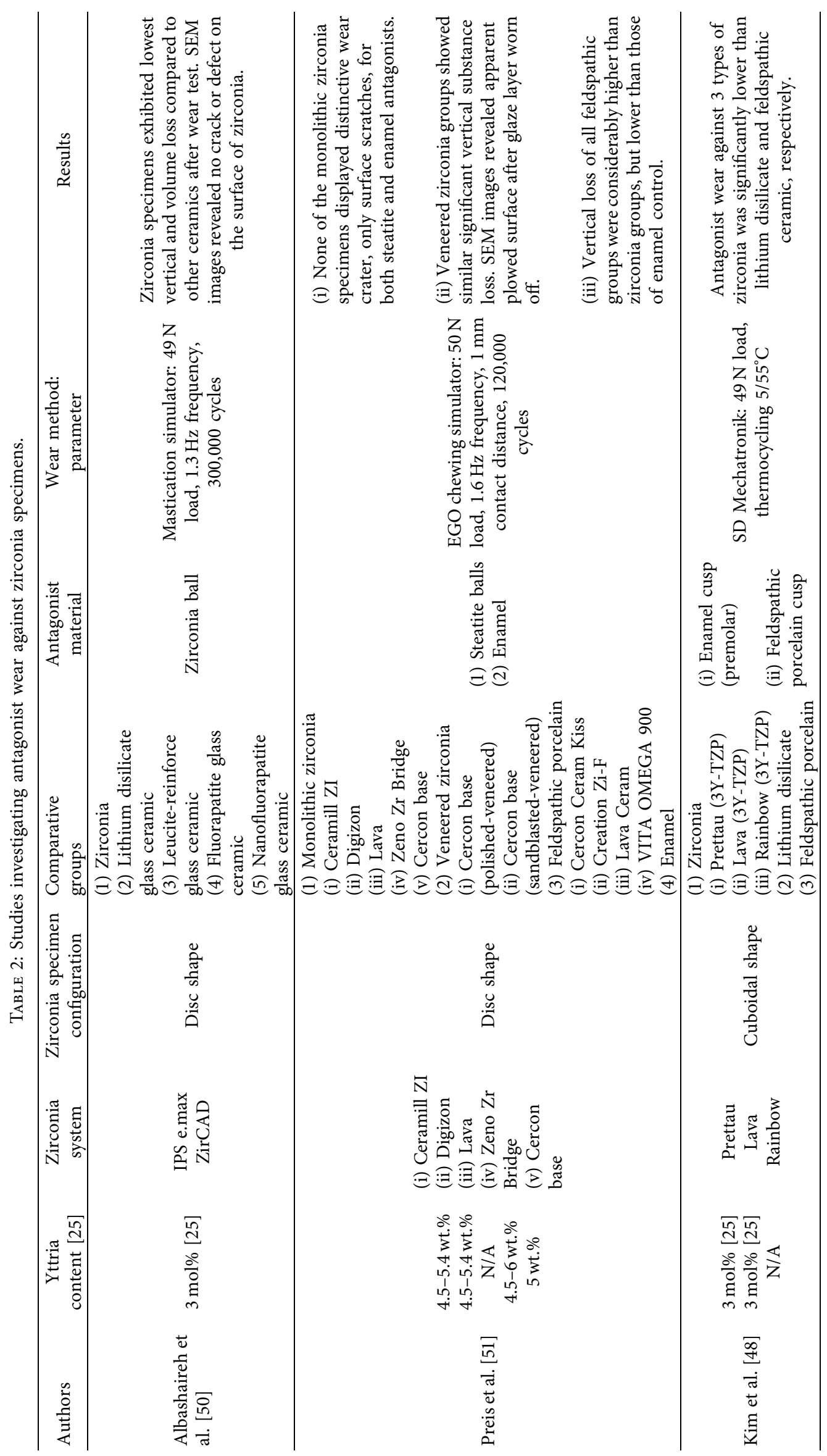




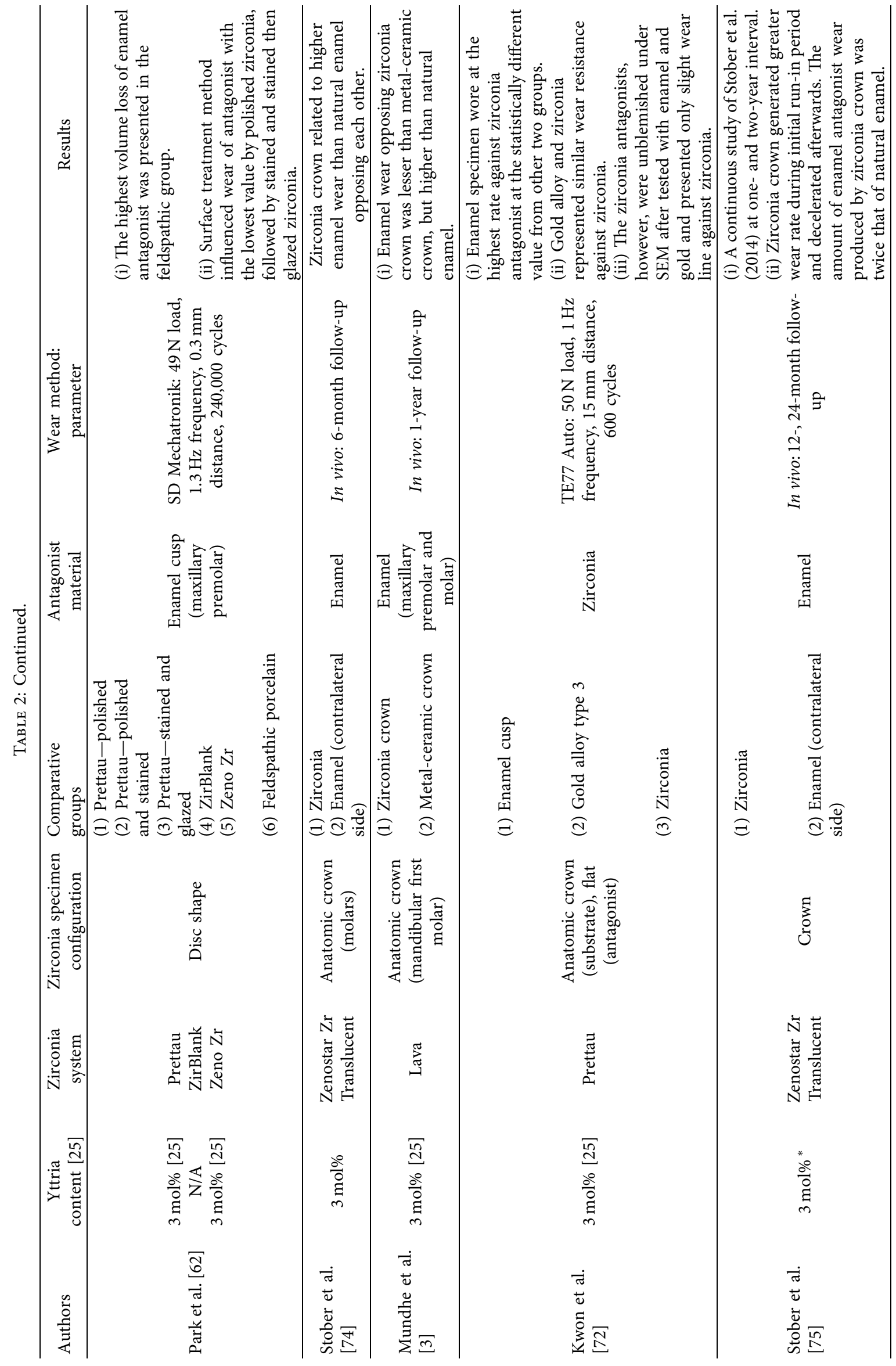




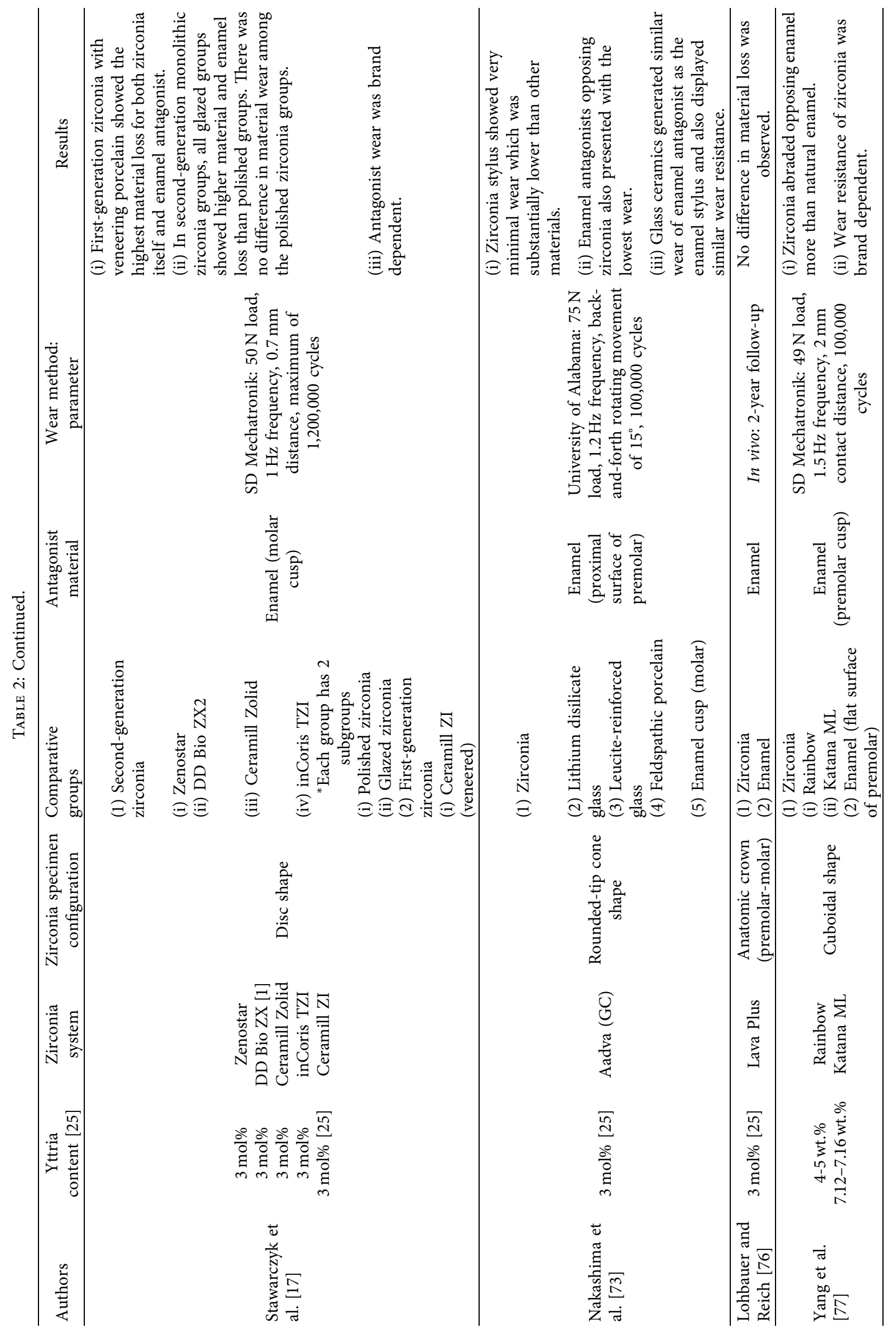




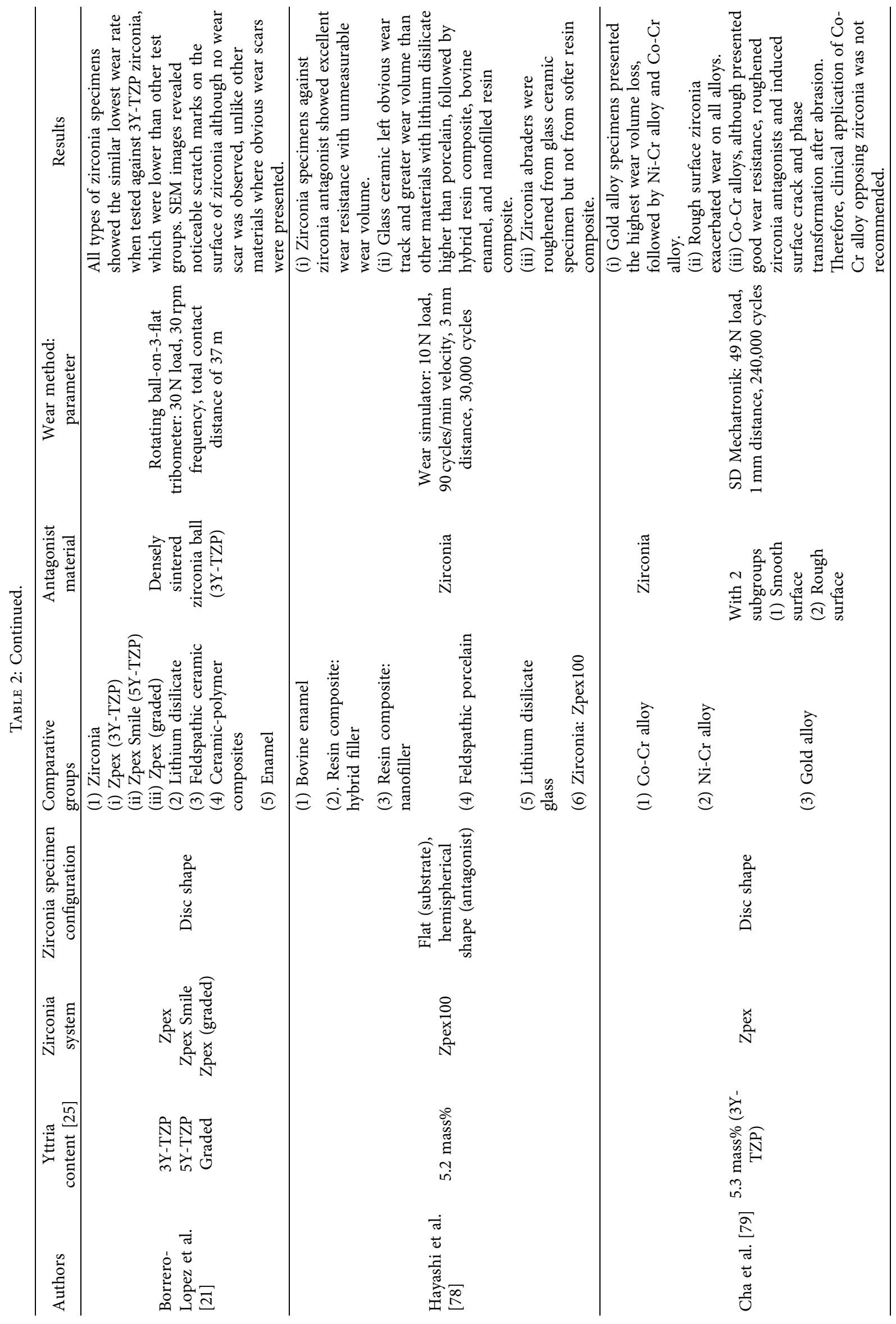




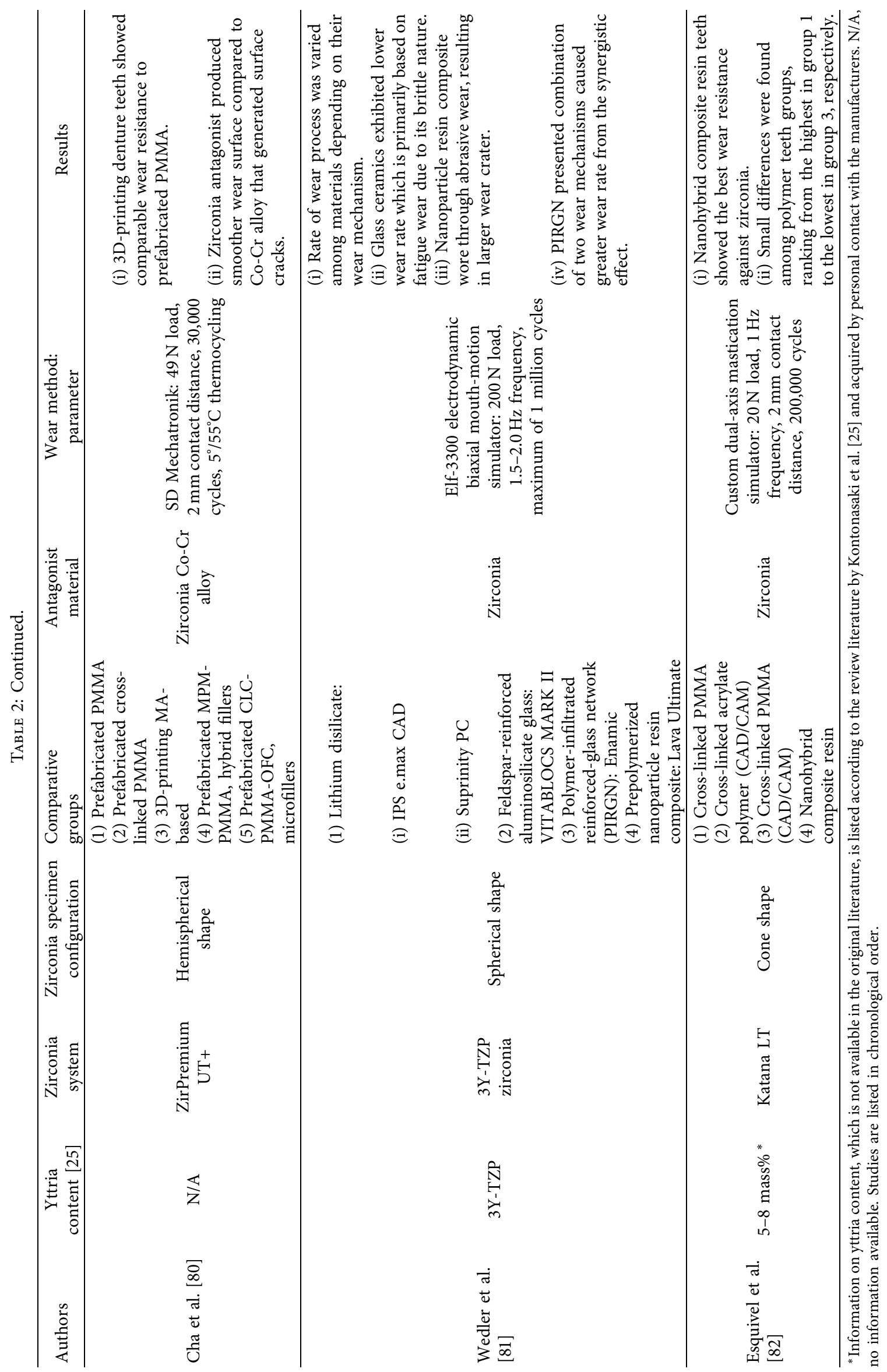


(iv) Filled composite resin denture teeth have improved wear resistance against 3Y-TZP zirconia restoration compared to unfilled PMMA denture teeth both prefabricated and CAD/CAM fabricated.

\section{Conclusion}

Based on this review of the literature, the following assumptions were drawn:

(i) Translucent zirconia compositions with increased yttria content (4Y- and 5Y-TZP), despite having different microstructural compositions, lower flexural strength, and lower fracture toughness, suggest equivalent wear resistance as conventional $3 \mathrm{Y}-\mathrm{TZP}$ from the literature revised.

(ii) Comparative studies evaluating wear of antagonist materials against zirconia compositions of different yttria content are still lacking. In the future, authors should be very specific in stating the zirconia composition used in scientific studies. Further studies regarding this issue are required.

\section{Data Availability}

The data used to support the findings of this study are included within the article.

\section{Conflicts of Interest}

The authors declare that they have no conflicts of interest.

\section{References}

[1] B. Stawarczyk, C. Keul, M. Eichberger, D. Figge, D. Edelhoff, and N. Lümkemann, "Three generations of zirconia: from veneered to monolithic. part II," Quintessence International, vol. 48, no. 6, pp. 441-450, 2017.

[2] T. Stober, N. Heuschmid, G. Zellweger, V. Rousson, S. Rues, and S. D. Heintze, "Comparability of clinical wear measurements by optical 3D laser scanning in two different centers," Dental Materials, vol. 30, no. 5, pp. 499-506, 2014.

[3] K. Mundhe, V. Jain, G. Pruthi, and N. Shah, "Clinical study to evaluate the wear of natural enamel antagonist to zirconia and metal ceramic crowns," The Journal of Prosthetic Dentistry, vol. 114, no. 3, pp. 358-363, 2015.

[4] I. Watanabe, C. Ohkubo, J. P. Ford, M. Atsuta, and T. Okabe, "Cutting efficiency of air-turbine burs on cast titanium and dental casting alloys," Dental Materials, vol. 16, no. 6, pp. 420-425, 2000.

[5] W.-S. Oh, R. Delong, and K. J. Anusavice, "Factors affecting enamel and ceramic wear: a literature review," The Journal of Prosthetic Dentistry, vol. 87, no. 4, pp. 451-459, 2002.

[6] R. R. Seghi, S. F. Rosenstiel, and P. Bauer, "Abrasion of human enamel by different dental ceramics in vitro," Journal of Dental Research, vol. 70, no. 3, pp. 221-225, 1991.

[7] R. DeLong, W. H. Douglas, R. L. Sakaguchi, and M. R. Pintado, "The wear of dental porcelain in an artificial mouth,” Dental Materials, vol. 2, no. 5, pp. 214-219, 1986.

[8] K. Shanmugam and R. Sahadevan, "Bioceramics-an introductory overview," in Fundamental Biomaterials: Ceramics, pp. 1-46, Elsevier, Amsterdam, Netherlands, 2018.
[9] H. P. Papanagiotou, S. M. Morgano, R. A. Giordano, and R. Pober, "In vitro evaluation of low-temperature aging effects and finishing procedures on the flexural strength and structural stability of Y-TZP dental ceramics," The Journal of Prosthetic Dentistry, vol. 96, no. 3, pp. 154-164, 2006.

[10] V. Koenig, C. P. Wulfman, M. A. Derbanne et al., "Aging of monolithic zirconia dental prostheses: protocol for a 5-year prospective clinical study using ex vivo analyses," Contemporary Clinical Trials Communications, vol. 4, pp. 25-32, 2016.

[11] V. Lughi and V. Sergo, "Low temperature degradation -agingof zirconia: a critical review of the relevant aspects in dentistry," Dental Materials, vol. 26, no. 8, pp. 807-820, 2010.

[12] S. Ghodsi and Z. Jafarian, "A review on translucent zirconia," The European Journal of Prosthodontics and Restorative Dentistry, vol. 26, no. 2, pp. 62-74, 2018.

[13] P. Baldissara, A. Llukacej, L. Ciocca, F. L. Valandro, and R. Scotti, "Translucency of zirconia copings made with different CAD/CAM systems," The Journal of Prosthetic Dentistry, vol. 104, no. 1, pp. 6-12, 2010.

[14] B. W. Marchack, S. Sato, C. B. Marchack, and S. N. White, "Complete and partial contour zirconia designs for crowns and fixed dental prostheses: a clinical report," The Journal of Prosthetic Dentistry, vol. 106, no. 3, pp. 145-152, 2011.

[15] I. Sailer, N. A. Makarov, D. S. Thoma, M. Zwahlen, and B. E. Pjetursson, "All-ceramic or metal-ceramic tooth-supported fixed dental prostheses (FDPs)? a systematic review of the survival and complication rates. part I: single crowns (SCs)," Dental Materials, vol. 31, no. 6, pp. 603-623, 2015.

[16] K. Nakamura, A. Harada, R. Inagaki et al., "Fracture resistance of monolithic zirconia molar crowns with reduced thickness," Acta Odontologica Scandinavica, vol. 73, no. 8, pp. 602-608, 2015.

[17] B. Stawarczyk, K. Frevert, A. Ender, M. Roos, B. Sener, and T. Wimmer, "Comparison of four monolithic zirconia materials with conventional ones: contrast ratio, grain size, fourpoint flexural strength and two-body wear," Journal of the Mechanical Behavior of Biomedical Materials, vol. 59, pp. 128-138, 2016.

[18] F. Zhang, M. Inokoshi, M. Batuk et al., "Strength, toughness and aging stability of highly-translucent Y-TZP ceramics for dental restorations," Dental Materials, vol. 32, no. 12, pp. e327-e337, 2016.

[19] F. Matsuzaki, H. Sekine, S. Honma et al., "Translucency and flexural strength of monolithic translucent zirconia and porcelain-layered zirconia," Dental Materials Journal, vol. 34, no. 6, pp. 910-917, 2015.

[20] F. Zhang, H. Reveron, B. C. Spies, B. Van Meerbeek, and J. Chevalier, "Trade-off between fracture resistance and translucency of zirconia and lithium-disilicate glass ceramics for monolithic restorations," Acta Biomaterialia, vol. 91, pp. 24-34, 2019.

[21] O. Borrero-Lopez, F. Guiberteau, Y. Zhang, and B. R. Lawn, "Wear of ceramic-based dental materials," Journal of the Mechanical Behavior of Biomedical Materials, vol. 92, pp. 144-151, 2019.

[22] M. Rosentritt, V. Preis, M. Behr, and T. Strasser, "Fatigue and wear behaviour of zirconia materials," Journal of the Mechanical Behavior of Biomedical Materials, vol. 110, Article ID 103970, 2020.

[23] S. J. Kwon, N. C. Lawson, E. E. McLaren, A. H. Nejat, and J. O. Burgess, "Comparison of the mechanical properties of translucent zirconia and lithium disilicate," The Journal of Prosthetic Dentistry, vol. 120, no. 1, pp. 132-137, 2018. 
[24] S. Vardhaman, M. Borba, M. R. Kaizer, D. Kim, and Y. Zhang, "Wear behavior and microstructural characterization of translucent multilayer zirconia," Dental Materials, vol. 36, no. 11, pp. 1407-1417, 2020.

[25] E. Kontonasaki, P. Giasimakopoulos, and A. E. Rigos, "Strength and aging resistance of monolithic zirconia: an update to current knowledge," Japanese Dental Science Review, vol. 56, no. 1, pp. 1-23, 2020.

[26] E. Kontonasaki, A. E. Rigos, C. Ilia, and T. Istantsos, "Monolithic zirconia: an update to current knowledge: optical properties, wear, and clinical performance," Dentistry Journal, vol. 7, no. 3, 2019.

[27] J. Yan, M. R. Kaizer, and Y. Zhang, "Load-bearing capacity of lithium disilicate and ultra-translucent zirconias," Journal of the Mechanical Behavior of Biomedical Materials, vol. 88, pp. 170-175, 2018.

[28] P. Nassary Zadeh, N. Lümkemann, B. Sener, M. Eichberger, and B. Stawarczyk, "Flexural strength, fracture toughness, and translucency of cubic/tetragonal zirconia materials," The Journal of Prosthetic Dentistry, vol. 120, no. 6, pp. 948-954, 2018.

[29] P. Baldissara, V. F. Wandscher, A. M. E. Marchionatti, C. Parisi, C. Monaco, and L. Ciocca, "Translucency of IPS e.max and cubic zirconia monolithic crowns," The Journal of Prosthetic Dentistry, vol. 120, no. 2, pp. 269-275, 2018.

[30] T. D. Church, J. P. Jessup, V. L. Guillory, and K. S. Vandewalle, "Translucency and strength of hightranslucency monolithic zirconium oxide materials," General Dentistry, vol. 65, no. 1, pp. 48-52, 2017.

[31] N. Ilie and B. Stawarczyk, "Quantification of the amount of blue light passing through monolithic zirconia with respect to thickness and polymerization conditions," The Journal of Prosthetic Dentistry, vol. 113, no. 2, pp. 114-121, 2015.

[32] Y. Zhang and J. R. Kelly, "Dental ceramics for restoration and metal veneering," Dental Clinics of North America, vol. 61, no. 4, pp. 797-819, 2017.

[33] G. K. R. Pereira, L. F. Guilardi, K. S. Dapieve, C. J. Kleverlaan, M. P. Rippe, and L. F. Valandro, "Mechanical reliability, fatigue strength and survival analysis of new polycrystalline translucent zirconia ceramics for monolithic restorations," Journal of the Mechanical Behavior of Biomedical Materials, vol. 85, pp. 57-65, 2018.

[34] G. K. R. Pereira, A. B. Venturini, T. Silvestri et al., "Lowtemperature degradation of Y-TZP ceramics: a systematic review and meta-analysis," Journal of the Mechanical Behavior of Biomedical Materials, vol. 55, pp. 151-163, 2015.

[35] J. Klimke, M. Trunec, and A. Krell, "Transparent tetragonal yttria-stabilized zirconia ceramics: influence of scattering caused by birefringence," Journal of the American Ceramic Society, vol. 94, no. 6, pp. 1850-1858, 2011.

[36] D. Longhini, C. Rocha, L. de Oliveira, N. Olenscki, E. Bonfante, and G. Adabo, "Mechanical behavior of ceramic monolithic systems with different thicknesses," Operative Dentistry, vol. 44, no. 5, pp. E244-E253, 2019.

[37] H. H. K. Xu, D. T. Smith, S. Jahanmir et al., "Indentation damage and mechanical properties of human enamel and dentin," Journal of Dental Research, vol. 77, no. 3, pp. 472-480, 1998.

[38] P. Lambrechts, M. Braem, M. Vuylsteke-Wauters, and G. Vanherle, "Quantitative in vivo wear of human enamel," Journal of Dental Research, vol. 68, no. 12, pp. 1752-1754, 1989.
[39] S. Heintze, "How to qualify and validate wear simulation devices and methods," Dental Materials, vol. 22, no. 8, pp. 712-734, 2006.

[40] R. DeLong, "Intra-oral restorative materials wear: rethinking the current approaches: how to measure wear," Dental Materials, vol. 22, no. 8, pp. 702-711, 2006.

[41] A. Koran, R. G. Craig, and E. W. Tillitson, "Coefficient of friction of prosthetic tooth materials," The Journal of Prosthetic Dentistry, vol. 27, no. 3, pp. 269-274, 1972.

[42] A. Ekfeldt and G. Øilo, "Occlusal contact wear of prosthodontic materials an in vivo study," Acta Odontologica Scandinavica, vol. 46, no. 3, pp. 159-169, 1988.

[43] K. T. Metzler, R. D. Woody, A. W. Miller 3rd, and B. H. Miller, "In vitro investigation of the wear of human enamel by dental porcelain," The Journal of Prosthetic Dentistry, vol. 81, no. 3, pp. 356-364, 1999.

[44] R. Belli, S. S. Scherrer, S. Reich, A. Petschelt, and U. Lohbauer, "In vivo shell-like fractures of veneered- $\mathrm{ZrO}_{2}$ fixed dental prostheses," Case Studies in Engineering Failure Analysis, vol. 2, no. 2, pp. 91-99, 2014.

[45] Y. Zhang, I. Sailer, and B. R. Lawn, "Fatigue of dental ceramics," Journal of Dentistry, vol. 41, no. 12, pp. 1135-1147, 2013.

[46] J. R. Kelly, I. Nishimura, and S. D. Campbell, "Ceramics in dentistry: historical roots and current perspectives," The Journal of Prosthetic Dentistry, vol. 75, no. 1, pp. 18-32, 1996.

[47] F. Zhang, B. C. Spies, J. Vleugels et al., "High-translucent yttria-stabilized zirconia ceramics are wear-resistant and antagonist-friendly," Dental Materials, vol. 35, no. 12, pp. 1776-1790, 2019.

[48] M.-J. Kim, S.-H. Oh, J.-H. Kim et al., "Wear evaluation of the human enamel opposing different Y-TZP dental ceramics and other porcelains," Journal of Dentistry, vol. 40, no. 11, pp. 979-988, 2012.

[49] M. Rosentritt, V. Preis, M. Behr, S. Hahnel, G. Handel, and C. Kolbeck, "Two-body wear of dental porcelain and substructure oxide ceramics," Clinical Oral Investigations, vol. 16, no. 3, pp. 935-943, 2012.

[50] Z. S. M. Albashaireh, M. Ghazal, and M. Kern, "Two-body wear of different ceramic materials opposed to zirconia ceramic," The Journal of Prosthetic Dentistry, vol. 104, no. 2, pp. 105-113, 2010.

[51] V. Preis, M. Behr, C. Kolbeck, S. Hahnel, G. Handel, and M. Rosentritt, "Wear performance of substructure ceramics and veneering porcelains," Dental Materials, vol. 27, no. 8, pp. 796-804, 2011.

[52] R. Jacobi, H. T. Shillingburg Jr, and M. G. Duncanson Jr, “A comparison of the abrasiveness of six ceramic surfaces and gold," The Journal of Prosthetic Dentistry, vol. 66, no. 3, pp. 303-309, 1991.

[53] S. Novak and M. Kalin, "The effect of $\mathrm{pH}$ on the wear of waterlubricated alumina and zirconia ceramics," Tribology Letters, vol. 17, no. 4, pp. 727-732, 2004.

[54] M. Kalin, G. Dražič, S. Novak, and J. Vižintin, "Wear mechanisms associated with the lubrication of zirconia ceramics in various aqueous solutions," Journal of the European Ceramic Society, vol. 26, no. 3, pp. 223-232, 2006.

[55] J. E. Choi, J. N. Waddell, K. M. Lyons, and J. A. Kieser, "Intraoral $\mathrm{pH}$ and temperature during sleep with and without mouth breathing," Journal of Oral Rehabilitation, vol. 43, no. 5, pp. 356-363, 2016.

[56] V. Preis, M. Schmalzbauer, D. Bougeard, S. Schneider-Feyrer, and M. Rosentritt, "Surface properties of monolithic zirconia after dental adjustment treatments and in vitro wear simulation," Journal of Dentistry, vol. 43, no. 1, pp. 133-139, 2015. 
[57] G. Mitov, S. D. Heintze, S. Walz, K. Woll, F. Muecklich, and P. Pospiech, "Wear behavior of dental Y-TZP ceramic against natural enamel after different finishing procedures," Dental Materials, vol. 28, no. 8, pp. 909-918, 2012.

[58] S. Janyavula, N. Lawson, D. Cakir, P. Beck, L. C. Ramp, and J. O. Burgess, "The wear of polished and glazed zirconia against enamel," The Journal of Prosthetic Dentistry, vol. 109, no. 1, pp. 22-29, 2013.

[59] V. Preis, F. Weiser, G. Handel, and M. Rosentritt, "Wear performance of monolithic dental ceramics with different surface treatments," Quintessence International, vol. 44, no. 5, pp. 393-405, 2013.

[60] L. Kontos, C. Schille, E. Schweizer, and J. Geis-Gerstorfer, "Influence of surface treatment on the wear of solid zirconia," Acta Odontologica Scandinavica, vol. 71, no. 3-4, pp. 482-487, 2013.

[61] N. C. Lawson, S. Janyavula, S. Syklawer, E. A. McLaren, and J. O. Burgess, "Wear of enamel opposing zirconia and lithium disilicate after adjustment, polishing and glazing," Journal of Dentistry, vol. 42, no. 12, pp. 1586-1591, 2014.

[62] J.-H. Park, S. Park, K. Lee, K.-D. Yun, and H.-P. Lim, “Antagonist wear of three CAD/CAM anatomic contour zirconia ceramics," The Journal of Prosthetic Dentistry, vol. 111, no. 1, pp. 20-29, 2014.

[63] B. J. Chong, A. K. Thangavel, S. B. Rolton, M. Guazzato, and I. J. Klineberg, "Clinical and laboratory surface finishing procedures for zirconia on opposing human enamel wear: a laboratory study," Journal of the Mechanical Behavior of Biomedical Materials, vol. 50, no. 93, pp. 93-103, 2015.

[64] G. E. Monasky and D. F. Taylor, "Studies on the wear of porcelain, enamel, and gold," The Journal of Prosthetic Dentistry, vol. 25, no. 3, pp. 299-306, 1971.

[65] M. Ghazal and M. Kern, "The influence of antagonistic surface roughness on the wear of human enamel and nanofilled composite resin artificial teeth," The Journal of Prosthetic Dentistry, vol. 101, no. 5, pp. 342-349, 2009.

[66] R. Amer, D. Kürklü, E. Kateeb, and R. R. Seghi, “Three-body wear potential of dental yttrium-stabilized zirconia ceramic after grinding, polishing, and glazing treatments," The Journal of Prosthetic Dentistry, vol. 112, no. 5, pp. 1151-1155, 2014.

[67] C. Goo, A. Yap, K. Tan, and A. Fawzy, "Effect of polishing systems on surface roughness and topography of monolithic zirconia," Operative Dentistry, vol. 41, no. 4, pp. 417-423, 2016.

[68] C. Park, M.-S. Vang, S.-W. Park, and H.-P. Lim, "Effect of various polishing systems on the surface roughness and phase transformation of zirconia and the durability of the polishing systems," The Journal of Prosthetic Dentistry, vol. 117, no. 3, pp. 430-437, 2017.

[69] N. Al-Haj Husain, J. Camilleri, and M. Özcan, "Effect of polishing instruments and polishing regimens on surface topography and phase transformation of monolithic zirconia: an evaluation with XPS and XRD analysis," Journal of the Mechanical Behavior of Biomedical Materials, vol. 64, pp. 104-112, 2016.

[70] Y. Zhang and B. R. Lawn, "Novel zirconia materials in dentistry," Journal of Dental Research, vol. 97, no. 2, pp. 140-147, 2018.

[71] Y.-S. Jung, J.-W. Lee, Y.-J. Choi, J.-S. Ahn, S.-W. Shin, and J.-B. Huh, "A study on thein-vitrowear of the natural tooth structure by opposing zirconia or dental porcelain," The Journal of Advanced Prosthodontics, vol. 2, no. 3, pp. 111-115, 2010.
[72] M.-S. Kwon, S.-Y. Oh, and S.-A. Cho, "Two-body wear comparison of zirconia crown, gold crown, and enamel against zirconia," Journal of the Mechanical Behavior of Biomedical Materials, vol. 47, pp. 21-28, 2015.

[73] J. Nakashima, Y. Taira, and T. Sawase, "In vitro wear of four ceramic materials and human enamel on enamel antagonist," European Journal of Oral Sciences, vol. 124, no. 3, pp. 295-300, 2016.

[74] T. Stober, J. L. Bermejo, P. Rammelsberg, and M. Schmitter, "Enamel wear caused by monolithic zirconia crowns after 6 months of clinical use," Journal of Oral Rehabilitation, vol. 41, no. 4, pp. 314-322, 2014.

[75] T. Stober, J. L. Bermejo, F. S. Schwindling, and M. Schmitter, "Clinical assessment of enamel wear caused by monolithic zirconia crowns," Journal of Oral Rehabilitation, vol. 43, no. 8, pp. 621-629, 2016.

[76] U. Lohbauer and S. Reich, "Antagonist wear of monolithic zirconia crowns after 2 years," Clinical Oral Investigations, vol. 21, no. 4, pp. 1165-1172, 2017.

[77] Y. J. Yang, Y. S. Choi, and H. J. Cha, "Bioinspired load-bearing hydrogel based on engineered sea anemone skin-derived collagen-like protein," Biotechnology Journal, vol. 13, no. 12, Article ID e1800086, 2018.

[78] S. Hayashi, S. Homma, T. Takanashi, T. Hirano, M. Yoshinari, and Y. Yajima, "Wear properties of esthetic dental materials against translucent zirconia," Dental Materials Journal, vol. 38, no. 2, pp. 250-256, 2019.

[79] M. S. Cha, Y. H. Huh, L. R. Cho, and C. J. Park, "A comparative study of the wear of dental alloys against monolithic zirconia," The Journal of Prosthetic Dentistry, vol. 123, 2019.

[80] H.-S. Cha, J.-M. Park, T.-H. Kim, and J.-H. Lee, "Wear resistance of 3D-printed denture tooth resin opposing zirconia and metal antagonists," The Journal of Prosthetic Dentistry, vol. 124, no. 3, pp. 387-394, 2020.

[81] M. Wendler, M. R. Kaizer, R. Belli, U. Lohbauer, and Y. Zhang, "Sliding contact wear and subsurface damage of CAD/CAM materials against zirconia," Dental Materials, vol. 36, no. 3, pp. 387-401, 2020.

[82] J. Esquivel, N. C. Lawson, E. Kee, K. Bruggers, and M. B. Blatz, "Wear of resin teeth opposing zirconia," The Journal of Prosthetic Dentistry, vol. 124, no. 4, pp. 488-493, 2020.

[83] Y.-S. Jang, T.-D. T. Nguyen, Y.-H. Ko et al., "In vitro wear behavior between enamel cusp and three aesthetic restorative materials: zirconia, porcelain, and composite resin," The Journal of Advanced Prosthodontics, vol. 11, no. 1, pp. 7-15, 2019.

[84] J. Gonzalez and R. Triplett, "Complications and clinical considerations of the implant-retained zirconia completearch prosthesis with various opposing dentitions," The International Journal of Oral \& Maxillofacial Implants, vol. 32, no. 4, pp. 864-869, 2017.

[85] P. Cardelli, F. P. Manobianco, N. Serafini, G. Murmura, and F. Beuer, "Full-arch, implant-supported monolithic zirconia rehabilitations: pilot clinical evaluation of wear against natural or composite teeth," Journal of Prosthodontics, vol. 25, no. 8, pp. 629-633, 2016.

[86] Z. Hao, H. Yin, L. Wang, and Y. Meng, "Wear behavior of seven artificial resin teeth assessed with three-dimensional measurements," The Journal of Prosthetic Dentistry, vol. 112, no. 6, pp. 1507-1512, 2014.

[87] M. Ghazal and M. Kern, "Wear of denture teeth and their human enamel antagonists," Quintessence International, vol. 41, no. 2, pp. 157-163, 2010. 